\title{
Role of lipids in the maintenance of neutral buoyancy by zooplankton
}

\author{
R. W. Campbell* , J. F. Dower \\ School of Earth \& Ocean Sciences, University of Victoria, PO Box 3055 Stn CSC, Victoria, British Columbia V8W 3P6, Canada
}

\begin{abstract}
Many types of zooplankton contain large proportions of lipids. Usually, these lipids represent energy storage compounds, but it has also been suggested that lipids play a role in buoyancy regulation. Lipids are thought to determine the overwintering depth of large calanoid copepods, and it has been widely assumed that these organisms overwinter at some 'depth of neutral buoyancy'. However, lipids are generally more compressible, and have a larger thermal expansion than seawater. This means that any depth of neutral buoyancy will be inherently unstable. Model results show that the ascent rates attributable to this instability are small at depth (where temperature changes are small), suggesting a simple way for animals to remain at depth while overwintering. However, model results also show that the buoyant properties of a copepod (or any small plankter) are extremely sensitive to its relative biochemical composition. This presents problems to maintaining vertical position, but may also be useful for vertical migrations.
\end{abstract}

KEY WORDS: Copepod · Zooplankton · Lipid · Buoyancy $\cdot$ Model $\cdot$ Depth distribution $\cdot$ Vertical migration

\section{INTRODUCTION}

Many planktonic organisms use lipids as an energy storage medium (Lee \& Hirota 1973, Childress \& Nygaard 1974, Sargent \& Falk-Petersen 1988). At atmospheric pressure, lipids are less dense than seawater; they often form a layer at the top of preserved zooplankton samples and have even been found to form surface slicks in the ocean (Lee \& Williams 1974). It is widely held that such lipids play a role in buoyancy control (Lewis 1970, Sargent \& Falk-Petersen 1988). However, a plausible mechanism by which lipids may be used to regulate buoyancy has yet to be proposed.

Yayanos et al. (1978) measured the density of a lipid mixture (primarily wax esters) extracted from the calanoid copepod Neocalanus plumchrus and observed the mixture to be more compressible, and to have a much higher thermal expansion, than seawater. They suggested that because of these properties, a lipid-rich plankter that is positively buoyant at the surface will become less so as it moves deeper in the water column. They concluded that lipids may initially repre- sent a 'barrier' to downward vertical migration, in that copepods are more buoyant at the surface than at depth, and must therefore overcome buoyancy forces when moving from shallow to deeper depths.

Building on this work, Visser \& Jónasdóttir (1999) fit a high order polynomial to the density measurements of Yayanos et al. (1978). Using that relationship, they produced a simple model for the density of a copepod in order to demonstrate how overwintering Calanus finmarchicus in the Faroe-Shetland channel can be positively buoyant at the surface, but neutrally buoyant at depth. Parameters for the Visser \& Jónasdóttir model were calculated from field and laboratory measurements, as well as with the assumption that the copepods were neutrally buoyant at their depth of overwintering. They found that the vertical ascent rate attributable to buoyancy forces could be considerable $\left(10 \mathrm{~s}\right.$ of $\left.\mathrm{m} \mathrm{d}^{-1}\right)$, particularly near the surface, where the density difference between seawater and lipids is greatest.

The pressure and temperature dependence of the mass density of lipids clearly has the potential to affect 
the way that lipid-rich planktonic organisms relate to and perceive the pelagic environment. Here, we propose that these properties may have a different relationship than that which has generally been assumed in the literature, and argue that the presence of large proportions of lipids requires some other buoyancy regulation mechanism(s) in the zooplankton.

\section{NEUTRAL BUOYANCY BY LIPIDS IS NOT STABLE}

Whether an animal floats or sinks depends on the density difference between it and the surrounding seawater. Thus, a neutrally buoyant animal must have the same aggregate density as the surrounding seawater. However, the greater compressibility of lipids compared to seawater means that any depth of neutral buoyancy will not be stable. In other words, below the depth of neutral buoyancy, lipid will become denser (as pressure increases), and thus the aggregate density of the animal will become greater as well. The converse is also true. Therefore, any displacement of the animal away from its depth of neutral buoyancy should result in it accelerating away from that depth. Hence, the presence of lipids is more than a barrier to downward migration (as suggested by Yayanos et al. 1978), or a means to promote upward migration (as suggested by Visser \& Jónasdóttir 1999); it actually represents an impediment to maintaining position in the water column. Moreover, as we will illustrate, the buoyancy properties of an animal are extremely sensitive to the relative composition of its biochemical constituents.

\section{ROLE OF LIPIDS IN BUOYANCY REGULATION: A COPEPOD EXAMPLE}

\section{A simple model for mass density}

Visser \& Jónasdóttir (1999; VJ99 hereafter) divided their model copepod into 3 components. At its simplest, the mass of the model copepod can be expressed as the sum of the masses of the components:

$$
m_{\text {copepod }}=m_{\text {water }}+m_{\text {lipid }}+m_{\text {other }}
$$

If rearranged in terms of density $(\rho)$ and volume ( $V$ i i.e. $m=\rho V$ ), this is equivalent to Eq. (3) of VJ99 (subscripts will be abbreviated hereafter). VJ99 further generalized their model with volume proportions (e.g. $V_{\mathrm{l}} / V_{\mathrm{c}}$ ). However, volume is not conservative with pressure (each component is compressible to some degree), whereas mass is, and so it is preferable to express the model in terms of mass proportions.
The density of the model copepod can also be expressed as:

$$
\rho_{\mathrm{c}}=\frac{m_{\mathrm{c}}}{V_{\mathrm{w}}+V_{\mathrm{l}}+V_{\mathrm{o}}}
$$

This is conceptually identical to the VJ99 model, in that the copepod is divided into 3 components (i.e. $V_{\mathrm{c}}=$ $V_{\mathrm{w}}+V_{\mathrm{l}}+V_{\mathrm{o}}$ ). Volume may be expressed in terms of mass and density (e.g. $V_{1}=m_{1} / \rho_{1}$ ), and mass proportions (e.g. $\delta_{1}=m_{1} / m_{\mathrm{c}}$ ) may then be substituted into Eq. (2) to yield:

$$
\rho_{\mathrm{c}}=\left(\frac{\delta_{\mathrm{w}}}{\rho_{\mathrm{w}}}+\frac{\delta_{\mathrm{l}}}{\rho_{\mathrm{l}}}+\frac{\delta_{\mathrm{o}}}{\rho_{\mathrm{o}}}\right)
$$

$\rho_{1}$ can be modeled as a function of temperature and pressure (using the polynomial of VJ99, their Eq. 2). $\rho_{\mathrm{w}}$ can be determined as a function of pressure, temperature and salinity (assuming osmotic equilibrium between the animal and the seawater around it) using the UNESCO seawater equation of state (Millero et al. 1980). $\rho_{0}$ represents the 'structural mass' of the copepod (e.g. protein, exoskeleton) and here will be held constant. VJ99 reported values for $\rho_{\mathrm{o}}$ of 1080 to $1240 \mathrm{~kg} \mathrm{~m}^{-3}$. Although the structural components are not completely incompressible, they are considerably less so than lipids. Kharakoz (2000) cites a coefficient of compressibility $(\beta)$ for protein on the order of 10 to $25 \times 10^{-6} \mathrm{bar}^{-1}$. By comparison, $\beta$ for copepod wax esters is of the order $6.5 \times 10^{-5}$ bar $^{-1}$ (calculated from Table 2 of Yayanos et al. [1978], using an exponential fit to volume data at $5.1^{\circ} \mathrm{C}$ ).

The change in seawater and lipid density with changes in pressure is generally quite small (of the order $1 \%$ over 100 bar). However, since it is the difference between these densities that drives buoyancy forces, even very small changes in density can result in large changes in ascent or decent rates. Furthermore, only small changes in the relative proportion of the 3 model constituents (i.e. lipid, water and 'other') are necessary to produce dramatic changes in the buoyancy properties of the model copepod. To demonstrate the sensitivity of the model to changes in the parameters, we have altered water and lipid contents while keeping $\rho_{\mathrm{o}}$ ('other') fixed, and calculated ascent rates given the density calculated for the model copepod (Fig. 1). To make the reformulated model comparable to that of VJ99, their volume proportions $\left(\alpha_{o}\right)$ were converted to mass proportions $\left(\delta_{1}\right.$ see Appendix 1). VJ99 chose their parameters given lipid:dry weight ratios from 0.29 (copepods used in laboratory measurements of density and lipid content) to 0.59 (representative of overwintering Calanus finmarchicus in the Faroe-Shetland Channel). To assess a likely parameter space for the model, the range of calculated ascent rates given those upper and lower limits is indicated within the shaded areas of Fig. 1. 
In the examples presented here, a 2\% change in water (and lipid) content is sufficient to achieve neutral buoyancy over the entire $850 \mathrm{~m}$ water column (dashed zero contours of Fig. 1). However, most parameter combinations result in a model copepod that is always positively or negatively buoyant, regardless of pressure. The first scenario of VJ99 ('Case 1'), overlaps the neutral buoyancy contour, while the second scenario ('Case 2') does not. Neither scenario is consistent with neutral buoyancy over the range of the only published observations of water content for Calanus finmarchicus ( 79 to $85 \%$ : Tande 1982). Obviously, there are countless parameter combinations to choose from. However, the points we wish to make are that (1) the model is very sensitive to the choice of parameters; and (2) the buoyancy properties of the model copepod are extremely sensitive to its relative biochemical content.

\section{Maintenance of overwintering depth}

In our example of Calanus finmarchicus in the Faroe-Shetland Channel, overwintering individuals are found primarily at depths below $600 \mathrm{~m}$, and appear to maintain their position at depth for periods of about 6 mo (Heath 1999). At those depths, even extremely small changes in the relative composition (parts per 1000) will result in very large changes in the buoyancy properties (100s of m). However, C. finmarchicus overwintering at depth are generally quiescent, and have not been observed to swim (Hirche 1996). How then are they able to maintain position during the overwintering period?

If we take an average water content of $82 \%$ (Tande 1982), and $\rho_{\mathrm{o}}=1260 \mathrm{~kg} \mathrm{~m}^{-3}$, neutral buoyancy occurs in the Faroe-Shetland Channel at approximately $690 \mathrm{~m}$
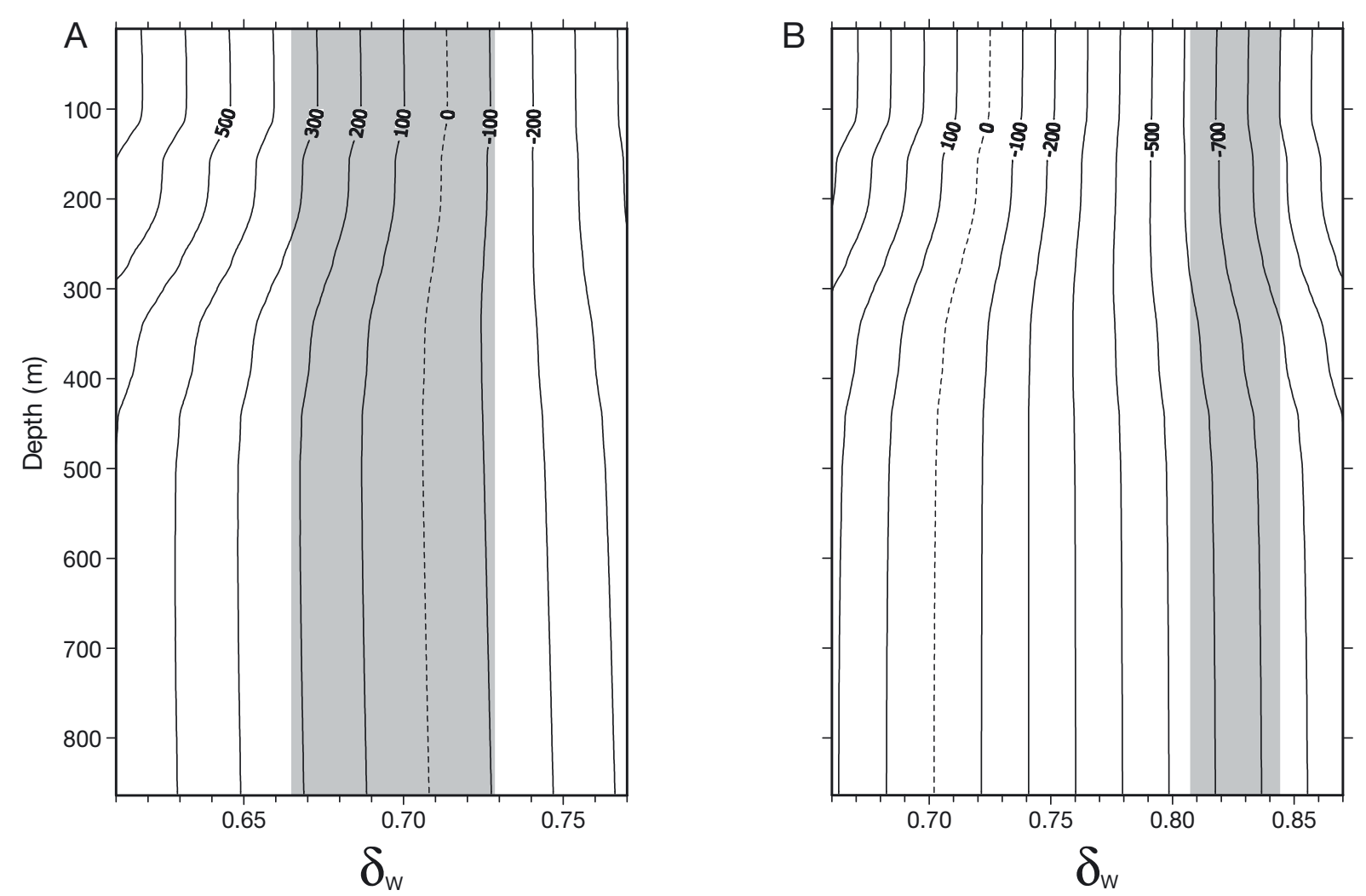

Fig. 1. Contours of velocity attributable to buoyancy ( $\mathrm{m} \mathrm{d}^{-1}$, positive upwards) of a model copepod as a function of relative chemical composition (based on data for overwintering Calanus finmarchicus from the Faroe-Shetland Channel, March 1995). Rates were calculated with model results for $\rho_{\mathrm{c}}$ and $\rho_{\text {seawater }}$ and Stokes' law $\left(w=g \Delta \rho d^{2} / 18 \mu\right.$, where $w$ is ascent rate in $\mathrm{m} \mathrm{s}^{-1}, g$ is acceleration due to gravity in $\mathrm{m} \mathrm{s}^{-2}, \Delta \rho$ is density difference in $\mathrm{kg} \mathrm{m}^{-3}, d$ is effective diameter in $\mathrm{m}$ and $\mu$ is absolute viscosity in $\mathrm{kg}^{-1}$ $\left.\mathrm{s}^{-1}\right)$. Effective diameter $(d)$ was $0.0013 \mathrm{~m}$ (Visser \& Jónasdóttir 1999) and $\mu$ was calculated as a function of pressure, temperature and salinity with the equation of Matthäus (1972; values ranged from $1.48 \times 10^{-3}$ to $\left.1.83 \times 10^{-3} \mathrm{~kg} \mathrm{~m}^{-3}\right)$. For these examples, $\delta_{0}$ has been held fixed, and $\delta_{\mathrm{w}}$ and $\delta_{1}$ have been varied such that $\delta_{\mathrm{w}}+\delta_{1}+\delta_{\mathrm{o}}=1$ (i.e. lipid increases in direct proportion to a decrease in water and vice versa). Neutral buoyancy $(w=0)$ is denoted by the dashed line. Parameter sets have been chosen to match those of Visser \& Jónasdóttir (1999): (A) 'Case 1' $\left(\delta_{0}=0.12, \rho_{0}=1080 \mathrm{~kg} \mathrm{~m}^{-3}\right)$, (B) 'Case 2' $\left(\delta_{0}=0.21, \rho_{0}=1240 \mathrm{~kg} \mathrm{~m}^{-3}\right)$. See Appendix 1 for details on conversion calculations. Grey boxes indicate 'likely parameter space' for $C$. finmarchicus given lipid to dry weight ratios between 0.29 and 0.59 


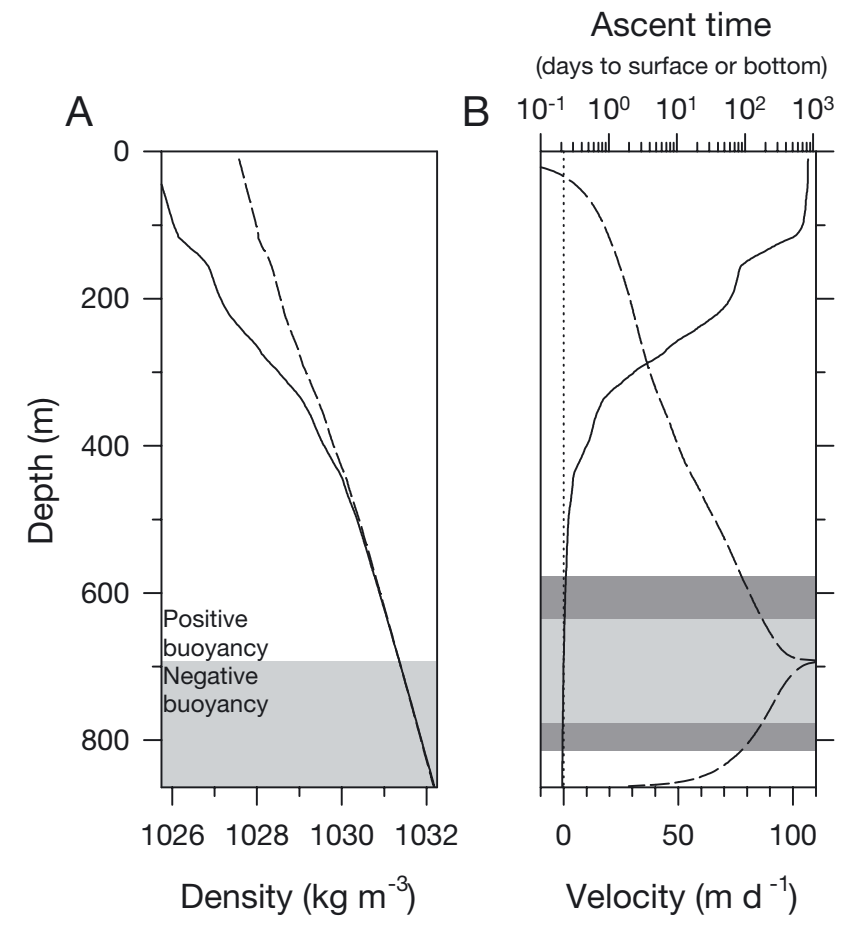

Fig. 2. (A) In situ seawater density (dashed line), Faroe-Shetland Channel, March 1995 (same data as Visser \& Jónasdóttir 1999, their Fig. 2) and calculated density for the model copepod $\left(\rho_{\mathrm{c}}\right.$ : solid line), given $\delta_{\mathrm{w}}=0.82, \delta_{\mathrm{l}}=0.11, \delta_{\mathrm{o}}=0.07$ and $\rho_{\mathrm{o}}=$ $1240 \mathrm{~kg} \mathrm{~m}^{-3}$. See text for details. (B) Ascent velocity (solid line, positive upwards) given the calculated density difference and calculated with Stokes' equation (see Fig. 1), and time to $10 \mathrm{~m}$ (i.e. surface) or $860 \mathrm{~m}$ (i.e. bottom; dashed line). The dark gray area encompasses the depth range within which a passive particle will take $90 \mathrm{~d}$ to reach the surface or bottom, the light gray area encompasses the depth range within which a passive particle will take $180 \mathrm{~d}$ to reach the surface or bottom

with $\delta_{1}=0.11$ and $\delta_{\mathrm{o}}=0.07$ (Fig. 2). This corresponds to a lipid:dry weight ratio of 0.61 , only slightly greater than the value of 0.59 given by VJ99 for lipid-rich Calanus finmarchicus from the Faroe-Shetland Channel. At depths near the point of neutral buoyancy, ascent rates are very low. The 'ascent time', the time it takes a passive particle to reach 10 or $860 \mathrm{~m}$ (i.e. the surface or the bottom), can be considerable. Positioning at or near the point of neutral buoyancy (e.g. between 635 and 777 m; Fig. 2) does however allow the animal to remain at depth for an extended period ( $\sim \mathrm{mo}$ ). In other words, if an animal is able to find its depth of neutral buoyancy during the summer/fall descent, one can expect it to maintain that position during the overwintering period, if changes in the biochemical constituents are ignored.

Metabolic rates in overwintering Calanus finmarchicus are quite low (Hirche 1996), but some expendi- ture of biochemical contents is to be expected. Lipid reserves are consumed over the overwintering period, particularly during the latter portions when gonadogenesis begins (Hopkins et al. 1984). Protein contents also decline (Orr 1934). In the case of our model copepod, we have assumed that its water component has the same density as seawater (as did VJ99). Consequently, the balance between the 'other' component (which is denser than seawater) and the lipid component (which is less dense than seawater) determines its overall buoyancy. Therefore, a decrease in lipid composition will reduce the upward buoyancy force, tending to make a neutrally buoyant animal become negatively buoyant. Similarly, a decrease in the 'other' component (e.g. protein) will tend to make a neutrally buoyant animal become positively buoyant. This balance between lipid and protein loss during the overwintering period may therefore partially balance each other in their effect on buoyancy. Currently, however, there is insufficient information about loss rates of either component to realistically model this effect.

\section{Termination of overwintering}

Termination of the overwintering state and moulting to adulthood by Calanus finmarchicus occurs at depth. Males appear first and move up slightly in the water column, to about $500 \mathrm{~m}$. Females appear shortly afterwards and migrate to the surface, where spawning occurs (Heath 1999). The maturation process is fueled by the lipid reserves, and will presumably alter the buoyancy properties of an animal (a reduction in the proportion of lipids tending to make the animal more negatively buoyant).

The model shows us that ascent rates are extremely sensitive to relative biochemical content (Fig. 1). The ascent rates presented here, and by VJ99, should therefore be viewed with caution. Moreover, if the assumption of osmotic equilibrium between the copepods and seawater is violated (see below), ascent rates will also be affected. However, the ascent rates calculated may be reasonable if one is willing to accept certain assumptions. If we assume that the copepod begins from a state of 'quasi neutral buoyancy', then as it moves actively towards the surface, its lipids will expand and upward buoyancy forces will increase, eventually resulting in positive ascent rates attributable to lipid expansion alone (Fig. 2). Above $500 \mathrm{~m}$, temperature begins to increase and ascent rates also rise, driven by the large thermal expansivity of the lipids. The ascent rates calculated here are comparable to those of VJ99 (their Figs. 4 \& 5). 


\section{IMPLICATIONS}

\section{Case for a buoyancy control mechanism in copepods}

For lipid-rich organisms like copepods and other zooplankton, any 'depth of neutral buoyancy' is not a stable position. This will be true for any animal that contains a large proportion of any substance that is more compressible (and/or has a larger thermal expansivity) than seawater. Although the model shows that the depth of neutral buoyancy is not stable, it also shows that ascent rates around some position of neutral buoyancy can be very small, permitting an animal to remain in the water column for long periods without adjustment (particularly in the case where temperature does not vary greatly with depth). However, the buoyancy properties of an individual are extremely sensitive to the relative biochemical composition (see above), and biochemical composition does change. In the example presented here, a change of only a few percent makes a tremendous difference on the buoyancy properties of the animal (Fig. 1). It is therefore not unreasonable to expect large changes in the buoyancy properties of individuals as they grow, mature and reproduce. It is also not unreasonable to expect them to possess a buoyancy control mechanism of some sort to deal with those changes.

Buoyancy regulation has not been observed in the Copepoda beyond the supralittoral harpacticoid copepods of the genus Tigriopus, which maintain negative buoyancy by altering their osmotic balance (McAllen et al. 1998). Ionic replacement, i.e. the selective transport of 'heavier' ions (e.g. $\mathrm{SO}_{4}{ }^{2-}$ and $\mathrm{Mg}^{2+}$ ) and replacement with either 'lighter' ions (e.g. $\mathrm{Na}^{+}, \mathrm{Cl}^{-}$and $\mathrm{NH}_{4}{ }^{+}$) or ions with a higher partial molal volume (e.g. trimethylamine, $\mathrm{Me}_{3} \mathrm{NH}_{4}{ }^{+}$), has been observed in other crustaceans (Sanders \& Childress 1988, Newton \& Potts 1993). In this way, an organism can remain isoosmotic with the surrounding seawater, while selectively reducing or increasing its aggregate density. Ion replacement has not yet been investigated in the pelagic Copepoda, but if it does occur, then the assumption that $\rho_{\mathrm{w}}=\rho_{\text {seawater }}$ used in our model is violated. Although it is currently unknown whether oceanic copepods are capable of buoyancy regulation, there is evidence that certain estuarine copepods (e.g. Acartia, Temora, Eurytemora and Centropages spp.) are capable of osmoregulation (Gaudy et al. 2000, Lance 1963, Roddie et al. 1984, Bayley 1969, respectively). If oceanic calanoids are able to exploit this pathway in order to alter water or ionic content, they should also be able to regulate their apparent buoyancy.

\section{Effects in surface waters}

Although the present example deals with overwintering calanoid copepods, it is important to note that both the steepest gradient of in situ seawater density and the greatest density contrast between the model copepod and seawater occur near the surface. This is driven by temperature, which has a larger effect on lipid mass density (although in terms of our example of overwintering copepods this is not relevant). Many copepods (as well as other zooplankton) undergo active diel vertical migrations of $10 \mathrm{~s}$ to $100 \mathrm{~s}$ of $\mathrm{m}$ (reviewed by Forward 1988, Pearre 2003). Presumably, they expend a significant deal of energy to do so, swimming being energetically quite costly to most zooplankton (Klyashtorin 1978, Torres et al. 1982, Mauchline 1998 and references therein). The strongest temperature and density gradients are almost always found in surface waters (Pickard \& Emery 1990), and so it is possible that even slight alterations to buoyancy (to aid ascend or descent) could represent considerable energetic savings to a vertically migrating animal.

For instance, the drag force $\left(F_{\mathrm{D}}\right.$ in $\left.\mathrm{N}\right)$ on a particle moving at intermediate Reynolds numbers can be calculated with Rayleigh's formula:

$$
F_{\mathrm{D}}=C_{\mathrm{D}}\left(1 /{ }_{2} \rho_{\mathrm{w}} U^{2} A\right)
$$

where $C_{\mathrm{D}}$ is the drag coefficient $\left(C_{\mathrm{D}}=24[1+\right.$ $\left.0.15 \operatorname{Re}^{0.687}\right] / \operatorname{Re}$ for $100>\operatorname{Re}>1$; Clift et al. 1978), $U$ is velocity $\left(\mathrm{m} \mathrm{s}^{-1}\right)$ and $A$ is the cross-sectional area $\left(\mathrm{m}^{2}\right)$. The buoyancy force $\left(F_{\mathrm{B}}\right)$ is:

$$
F_{\mathrm{B}}=m \times g\left(\frac{\rho_{\mathrm{w}}}{\rho_{\mathrm{c}}}-1\right)
$$

where $m$ is mass $(\mathrm{kg})$ and $g$ is acceleration due to gravity $\left(\mathrm{m} \mathrm{s}^{-2}\right.$; Glickman 2000). With the parameters in the example given here for Calanus finmarchicus (Fig. 2), assuming a wet weight of $1000 \mu \mathrm{g}$ (Tande 1982) and a swimming speed of $1 \mathrm{~cm} \mathrm{~s}^{-1}, F_{\mathrm{D}} \approx\left(10^{0}\right)\left(10^{3}\right)\left(10^{-4}\right)\left(10^{-6}\right)$ $\approx 10^{-7} \mathrm{~N}$ and $F_{\mathrm{B}} \approx\left(10^{-3}\right)\left(10^{1}\right)\left(10^{-3}\right) \approx 10^{-5} \mathrm{~N}$ at the surface. At the depth of neutral buoyancy, $F_{D}$ is essentially unchanged, while $F_{\mathrm{B}}=0$.

Clearly, buoyancy forces can be much greater than drag forces, although the latter will be size- and velocity-dependent. However, since the buoyancy force increases as depth decreases (i.e. the animal accelerates), any organism exploiting this mechanism to move upwards must possess a way to rapidly change mass density in order to stop its ascent when nearing the surface. Similarly, any animal moving downwards from quasi-neutral buoyancy at the surface will experience progressively less buoyancy force as it descends, and will need to change its mass density in order to stop sinking once the desired depth has been reached. 
Given the large thermal expansion of lipids, it is possible for true neutral buoyancy to occur in areas where temperature increases with depth. An increase in temperature decreases lipid density, so that an animal moving deeper will experience an increase in the upward buoyancy forces of its lipids. Conversely, a move upwards would cause an increase in lipid density and a decrease in upward buoyancy forces. Increases in temperature with depth do occur in neritic zones (e.g. Gulf of Maine) and large estuaries (e.g. Gulf of St. Lawrence) and could be exploited in those areas by plankton to achieve neutral buoyancy. Again, whether an individual can passively achieve neutral buoyancy, or be positively or negatively buoyant over the entire water column, will depend on its relative chemical composition.

\section{Measurements of mass density and acoustic backscatter}

The fact that lipids are more compressible than seawater also suggests that measurements of mass density made at atmospheric pressure (Knutsen et al. 2001 and references therein) are underestimates of in situ values. Because lipid constituents will expand following collection at depth, mass density measured at the surface will be greater than mass density under pressure. Similarly, mass density measurements will be affected by the temperature at which they are made. However, the greater thermal expansivity of lipids means that it is much more important that measurements be made at the in situ temperature from which the animals were collected. Measurements of mass density at in situ temperature and pressure certainly add to the already considerable methodological challenges of measuring mass density (reviewed by Knutsen et al. 2001), but they are not insurmountable.

The differential compressibility of lipids also has practical implications. Measurements of acoustic backscatter are commonly used to estimate zooplankton biomass. Acoustic backscatter, however, is extremely sensitive to the density contrast between the ensonified particles and the fluid they are suspended in (Greenlaw 1979, Køgeler et al. 1987). The effect is strongly size- and frequency-dependent, but Knutsen et al. (2001) report a $1 \%$ change in density causing a $2 \mathrm{~dB}$ change in backscatter. There have been measurements of the density contrast of several types of zooplankton, particularly euphausiids and copepods (see Knutsen et al. 2001), but all have been made at atmospheric pressure. That density contrast changes with depth and temperature (and perhaps even change sign) is a potentially confounding factor for in situ measurements of acoustic backscatter.

\section{CONCLUSIONS}

The high compressibility of lipids makes any position of neutral buoyancy unstable. Although we use a copepod example, this principle holds true for any organism containing a large proportion of any substance more compressible than seawater. It follows, then, that a lipid-rich organism attempting to maintain neutral buoyancy will have to actively maintain that position in some way. The model also shows that the density difference (and resulting buoyancy force) is highly sensitive to changes in the relative chemical composition of the organism (with some assumptions, outlined above). Again, this will apply to any organism (copepod or otherwise) that does not actively maintain its buoyancy in some way. In fact, since ascent or descent rates at low Reynolds numbers scale with the square of size, larger organisms (e.g. decapods, cnidarians and fish) should ascend or descend at much greater rates than those presented here. This mechanism for moving up and down in the water column could result in significant energetic savings for animals undergoing large vertical migrations on a regular basis (e.g. Euphausiids, Mychtophids).

Acknowledgements. We thank M. R. Heath for providing TS data for the Faroe-Shetland Channel, and S. E. Allen, T. J. Miller and 3 anonymous reviewers for their comments on earlier versions of the manuscript. This work was supported by a University of Victoria Graduate Fellowship to R.W.C. and an NSERC (Natural Sciences and Engineering Research Council of Canada) Discovery grant to J.F.D.

\section{LITERATURE CITED}

Bayley IAE (1969) The body fluids of some Centropagid copepods: total concentration and amounts of sodium and magnesium. Comp Biochem Physiol 28:1403-1409

Childress JJ, Nygaard M (1974) Chemical composition and buoyancy of midwater crustaceans as function of depth of occurrence off southern California. Mar Biol 27:225-238

Clift R, Grace JR, Weber M (1978) Bubbles, drops, and particles. Academic Press, New York

Forward RB (1988) Diel vertical migration: zooplankton photobiology and behaviour. Oceangr Mar Biol Annu Rev 26:361-393

Gaudy R, Cervetto G, Pagano M (2000) Comparison of the metabolism of Acartia clausi and A. tonsa: influence of temperature and salinity. J Exp Mar Biol Ecol 247:51-65

Glickman TS (2000) Glossary of meteorology, 2nd edn. American Meteorological Society, Boston

Greenlaw CF (1979) Acoustical estimation of zooplankton populations. Limnol Oceanogr 24:226-242

Heath MR (1999) The ascent migration of Calanus finmarchicus from overwintering depths in the Fareo-Shetland Channel. Fish Oceanogr 8(Suppl 1):84-99

Hirche HJ (1996) Diapause in the marine copepod, Calanus finmarchicus - a review. Ophelia 44:129-143

Hopkins CCE, Tande KS, Gronvik S, Sargent JR (1984) Ecological investigations of the zooplankton community of 
Balsfjorden, northern Norway: an analysis of growth and overwintering tactics in relation to niche and environment in Metridia longa (Lubbock), Calanus finmarchicus (Gunnerus), Thysanoessa inermis (Kroyer) and T. rasschi (M. Sars). J Exp Mar Biol Ecol 82:77-99

Kharakoz DP (2000) Protein compressibility, dynamics, and pressure. Biophys J 79:511-525

Klyashtorin LB (1978) Estimation of energy expenditures for active swimming and vertical migrations in planktonic crustaceans. Oceanology 18:91-94

Knutsen T, Melle W, Calise L (2001) Determining the mass density of marine copepods and their eggs with a critical focus on some of the previously used methods. J Plankton Res 23:859-873

Køgeler JW, Falk-Petersen S, Kristensen A, Pettersen F, Dalen J (1987) Density- and sound speed contrasts in sub-arctic zooplankton. Polar Biol 7:231-235

Lance J (1963) The salinity tolerances of some estuarine planktonic crustaceans. Biol Bull 127:108-118

Lee RF, Hirota J (1973) Wax esters in tropical zooplankton and nekton and the geographical distribution of wax esters in marine copepods. Limnol Oceanogr 18:227-239

Lee RF, Williams PM (1974) Copepod 'slick' in the northwest Pacific Ocean. Naturwissenschaften 61:505-506

Lewis RW (1970) The densities of three classes of marine lipids in relation to their possible role as hydrostatic agents. Lipids 5:151-152

Matthäus DJ (1972) Die Viskosität des Meerwassers. Beitr Meereskd 29:93-107

Mauchline J (1998) The biology of calanoid copepods. Adv Mar Biol 33:1-710

McAllen RJ, Taylor AC, Davenport J (1998) Osmotic and body density response in the harpacticoid copepod Tigriopus brevicornis in supralittoral rock pools. J Mar Biol Assoc UK 78:1143-1153

Millero FJ, Chen CT, Bradshaw A, Schleicher K (1980) A new high pressure equation of state for seawater. Deep-Sea Res I 27:255-264
Newton C, Potts WTW (1993) Ionic regulation and buoyancy in some planktonic organisms. J Mar Biol Assoc UK 73:15-23

Orr AP (1934) On the biology of Calanus finmarchicus. IV. Seasonal change in the weight and chemical composition in Loch Fyne. J Mar Biol Assoc UK 19:613-632

Pearre S (2003) Eat and run? The hunger/satiation hypothesis in vertical migration: history, evidence and consequences. Biol Rev 78:1-79

Pickard GL, Emery WJ (1990) Descriptive physical oceanography. Butterworth Heinemann, Oxford

Roddie BD, Leakey RJG, Berry AJ (1984) Salinity-temperature tolerance and osmoregulation in Eurytemora affinis (Poppe) (Copepoda: Calanoida) in relation to its distribution in the zooplankton of the upper reaches of the Forth estuary. J Exp Mar Biol Ecol 79:191-211

Sanders NK, Childress JJ (1988) Ion replacement as a buoyancy mechanism in a pelagic deep-sea crustacean. J Exp Biol 138:333-343

Sargent JR, Falk-Petersen S (1988) The lipid biochemistry of calanoid copepods. Hydrobiologia 167/168:101-114

Tande KS (1982) Ecological investigations on the zooplankton community of Balsfjorden, northern Norway: generation cycles, and variations in body weight and body content of carbon and nitrogen related to overwintering and reproduction in the copepod Calanus finmarchicus (Gunnerus). J Exp Mar Biol Ecol 62:129-142

Torres JJ, Childress JJ, Quetin LB (1982) A pressure vessel for the simultaneous determination of oxygen consumption and swimming speed in zooplankton. Deep-Sea Res 29: 631-639

Visser AW, Jónasdóttir SH (1999) Lipids, buoyancy and the seasonal vertical migration of Calanus finmarchicus. Fish Oceanogr 8(Suppl 1):100-106

Yayanos AA, Benson AA, Nevenzel JC (1978) The pressurevolume-temperature (PVT) properties of a lipid mixture from a marine copepod, Calanus plumchrus: implications for buoyancy and sound scattering. Deep-Sea Res 25: $257-268$

Appendix 1. Conversion of volume proportions to mass proportions

To convert volume proportions $(\alpha)$ to mass proportions $(\delta)$, the volume proportion $\alpha_{0}=V_{\mathrm{o}} / V_{\mathrm{c}}$ may be rearranged (since $V=m / \rho$ ) to:

$$
m_{\mathrm{c}}=\frac{m_{\mathrm{o}} \rho_{\mathrm{c}}}{\alpha_{\mathrm{o}} \rho_{\mathrm{o}}}
$$

and substituted into the expression for mass proportion $\left(\delta_{0}=m_{0} / m_{c}\right)$ :

$$
\delta_{\mathrm{c}}=\frac{\alpha_{\mathrm{o}} \rho_{\mathrm{o}}}{\rho_{\mathrm{c}}}
$$

In this case, $\rho_{c}$ is the density of the model copepod as given by the model of Visser \& Jónasdóttir (1999), which varies with depth. The calculated value of $\delta_{0}$ thus decreases with depth, a consequence of the volume proportion being fixed in their model. Visser \& Jónasdóttir (1999) measured parameters at atmospheric pressure, so the value of $\delta_{0}$ at the minimum depth $(10 \mathrm{~m})$ was used. For their 'Case 1 ' situation $\left(\alpha_{0}=0.2\right.$, $\left.\rho_{\mathrm{o}}=1080 \mathrm{~kg} \mathrm{~m}^{-3}\right), \delta_{\mathrm{o}}$ varied from 0.2106 (surface) to 0.2095 (maximum depth). For 'Case 2' $\left(\alpha_{0}=0.1, \rho_{0}=1260 \mathrm{~kg} \mathrm{~m}^{-3}\right)$, $\delta_{0}$ varied from 0.1210 (surface) to 0.1202 (maximum depth).
Editorial responsibility: Thomas Kiørboe (Contributing Editor), Charlottenlund, Denmark
Submitted: October 21, 2002; Accepted: August 18, 2003 Proofs received from author(s): October 16, 2003 